\title{
Determinants of household energy efficiency and electricity consumption in Uganda
}

\author{
Muwanga ALLAN ${ }^{1}$ and Ru Guo ${ }^{2}$ \\ ${ }^{1}$ UN Environment Tongji-Institute of Environmental for Sustainable Development, College of Environmental Science and Engineering, Tongji \\ University, Shanghai 200092, China. \\ ${ }^{2}$ College of Environmental Science and Engineering, Tongji University, 1239 Siping Road, Shanghai 200092, P.R. China
}

DOI: 10.29322/IJSRP.11.08.2021.p11629

http://dx.doi.org/10.29322/IJSRP.11.08.2021.p11629

\begin{abstract}
Sustaining energy consumption and enhancing energy efficiency remain key policy issues in Uganda. This paper employs a stochastic frontier analysis (SFA) to analyze the determinants of household energy consumption and efficiency in Uganda. The study utilized data collected from 344 domestic energy consumers in Uganda. Stochastic energy frontier results indicate that mean electrical efficiency for domestic electricity consumers was 74.5 percent. The results show that domestic energy users were inefficient and the potential loss in household electricity consumption was $123.79 \mathrm{kWh}$ due to the inefficiency translating into an annual income loss of 88,437 Uganda shillings (UGX). The results indicate that energy price and household income do matter as they create significant variations in household energy usage. The paper also highlights that household size and power availability had a negative and significant influence electricity efficiency while level of education enhanced electricity efficiency at household level. Based on the findings, there is still room to improve electricity efficiency with the existing conservation technologies and management practices. This calls for the need to promote energy conservation actions and influence household decision-making. Additionally, electricity saving by stimulation and support measures including introduction of new methods of energy consumption and management, educating people through the electronic and print media and providing financial incentives in the form of subsidies in the price of electricity efficient materials. The need to ensure sustainable consumption of energy through introducing higher energy efficiency standards for electrical appliances and diversifying household income sources. Furthermore, strategies for enhancing energy efficiency should focus on specific groups that tend to exhibit higher inefficiency in electricity usage. Hence, the decrease of electricity efficiency driven by the change of household size should be a matter of concern.
\end{abstract}

Index Terms- Energy efficiency, Household, Stochastic energy frontier, Sustainable energy consumption

\section{INTRODUCTION}

$\mathrm{E}$ nergy is a fundamental input for production of goods and services and an engine for sustainable economic growth and development for all countries [1]. Globally, electricity is the second most used source of energy worldwide after petrol and today it represents 19 percent of total consumption [2]. About 70 percent of the world's renewable energy needs are from hydroelectricity which is the leading source of electricity generation; and has been growing faster than other renewable sources since early in the $21^{\text {st }}$ century [3]. This rapid growth and urbanization is pushing the share of electricity towards a 20 percent share in total final consumption of energy [2].

In Sub-Saharan Africa, 89 percent of the population (about more than 580 million people) lack access to clean energy and more millions are connected to an unreliable grid that does not meet their daily energy service needs [4]. The household electrification rate in sub-Saharan Africa is the lowest compared to other developing regions in the world, around 43 percent despite many programs providing access for 76 million people since 2014 [5]. Nonetheless, the 76 million new connections have slightly outpaced population growth of 54.5 million people. In terms of absolute number of people living without electricity has fallen only by 21 million [5]. Most countries in this region have energy access rates of about 20 percent, and two out of three (2/3) people lack access to modern energy services [6]. Low household incomes coupled with inefficient and costly forms of energy supply, make electricity affordability a critical issue. Sustainable energy efficiency enables to reduce energy investment requirement, and make the best use of existing supply capacities to improve the access to energy [7].

Electricity energy efficiency is also a critically important component of increasing access to modern electricity services at household level. However, harnessing energy efficiency is a complex endeavour that requires first assessing the energy efficiency potential at household level and identifying barriers that limit households' investment in energy efficiency $[8,9]$. For households consuming electricity from the power grid, energy efficiency lowers utility costs, freeing up incomes that can be used for other business investments or increased energy services [10]. Empirical evidence 
available on residential energy and efficiency in Uganda indicates a strong correlation between household characteristics, institutional factors on sustainable energy and efficiency among households and within developing cities. In order to better understand the link between electricity consumption and efficiency and the influencing factors at household level, a theoretical stochastic frontier model by Alberini and Filippini [11], Filippini and Hunt [12] was utilized. Specifically, this paper therefore sought to determine the level of electricity efficiency at household level and find out the socio-economic household characteristics and institutional factors that influence household energy use and efficiency as a pathway to energy sustainability in Uganda.

\section{BACKGROUND}

\subsection{Energy efficiency and Energy Poverty in Uganda}

Energy efficiency is among the competing strategic priorities in Uganda and is generally considered as short-term answer to power outages and blackouts without considering energy source for subsequent electricity planning [8].

Many countries including Uganda recognize the need to understand how effectively energy is being consumed so that they can increase energy efficiency [13]. In Uganda, numerous stakeholders largely neglect the relationship between energy efficiency and energy demand including multiple merits of energy efficiency for quality and amount of energy available [8]. For instance, energy efficiency can increase energy access to 18 percent of rural customers in Uganda [8]. This illustrates a significant opportunity for electricity energy efficiency to cost-effectively benefit the household economy including on-grid residential lighting. Thus improving the energy efficiency at household level presents an excellent opportunity to reduce greenhouse gas emissions [14]. However, the extent to which these benefits can actually be realized will greatly depend on consumer preferences, incomes, supply infrastructure, and other market features [15]. It is evident that Uganda is witnessing increased population growth which is associated with increased energy demand and consumption in all facets of the economy. The increased electricity energy demand and the prevailing inefficient pattern of consumption coupled with the associated socio-economic characteristics and institutional issues in electricity efficiency has been a cause for concern. Therefore, establishing the level of electricity energy efficiency at household level could play a valuable role in guiding housing stakeholders and the public on the level of energy savings and practices required to enhance electricity energy efficiency [16].

Energy efficiency eliminates energy poverty, reducing demand for energy imports, and lowering our costs on a household and economy-wide level [17, 18]. Energy efficiency improvement has long been supported as a way to enhance the output and sustainability of an economy, mostly by saving energy. The effect of energy efficiency can also be a significant contributor to socio-economic growth and development [19]. Energy efficiency and energy access are sometimes perceived as conflicting priorities for funding rather than components that can work collectively to attain access to energy services [20].

\subsection{Household incomes and size as the determinants of energy efficiency}

A vast amount of literature shows that household income level is positively related to energy efficiency investments [21,22]. There may be varying reasons for this. If a household belongs to a low income group, it would be very likely to consume less amounts of energy as a cost saving measure and would not have the ability to respond to calls for greater conservation activity [21]. The restricted access to credit and transactions costs (such as time and effort) also makes household conservation actions prohibitive for low income households [23]. In contrast, SF Gamtessa [24] argues that high-income households are less likely to undertake retrofit investment, possibly because energy expenditure accounts for a very small share of their income. Some studies have concluded that most low-income households keep up with their energy bills but typically cut back on food and heating [25, 26]. This situation exacerbates other negative effects caused by poor energy efficiency in these households and call for more robust energy efficiency measures. Improving energy efficiency of low-income households is crucial for the long-term solution to energy poverty. Energy efficiency results in multiple benefits beyond the reduction of primary or final energy consumption [27].

Factors such as household size and the number of young children in the household are suggested to have a direct effect on energy saving behaviour [28]. This is because household size is positively related to the electricity consumed. Hence residences with large household size consume more electricity. This is supported by A Otsuka [29] study in Japan that employed a stochastic energy demand frontier and found out that increase in household size by 10 percent resulted into an increase in energy demand per household by 1.63 percent holding other factors constant

\subsection{Price of electricity and power availability as the determinants of energy efficiency}

This publication is licensed under Creative Commons Attribution CC BY.

http://dx.doi.org/10.29322/IJSRP.11.08.2021.p11629

WwW.ijsrp.org 
ISSN 2250-3153

Different studies have shown that household energy consumption varies with electricity price. For instance T Dergiades and L Tsoulfidis [30] revealed that electricity consumption is very sensitive to price in the long run. Whereas other studies based on state level panel data reported that electricity consumption is relatively insensitive to price especially in the short term [11, 31]. According to H Winkler, AF Simões, EL La Rovere, M Alam, A Rahman and S Mwakasonda [32] study in developing countries, poor households' ability to afford their preferred energy sources such as electricity is particularly vulnerable to price fluctuations, making it too expensive to purchase.

Regarding power availability, there is sporadic increase in the development of modern buildings, and these buildings require a cost-effective and sustainable source of energy[33]. Uganda among other African countries have major energy shortage issues due to the insufficient power supply and distribution facilities. Electrical power generation and supply are grossly inadequate in Uganda for both commercial and domestic uses. The inadequate supply and availability of needed energy are a challenge to sustainable development of the built environment [33]. In spite of this setback, there is a significant increase in real estate development in Uganda and in Africa generally due to the increasing population and demand pressure for housing [34]. To compensate for the insufficient and unreliable energy from the Power Holding Company, domestic users have resorted to other alternative power sources some of which are expensive

\subsection{Research Problem}

Many developing countries including Uganda face the challenges of low energy accessibility rate, power loss and inadequate supply to meet the growing demand. Currently, over 79.6 percent of the population in Uganda does not have access to clean energy, and household electricity access is the lowest in the world [35]. Additionally, Uganda also faces low production capacity amidst increasing energy use of 8.2 percent annually, translating into 125,000 new customers every year [8]. By 2030, it is estimated that the demand of the grid-connected residential sector will have grown by more than 250 percent from current levels which remains the significant challenge to attain [36].

Despite the government's effort to put in place institutions to support and solve energy access issues like the Rural electrification Agency and inclusion of energy among the sustainable development goals "SDG7" by the United Nations, applicability especially in developing countries is still lacking. While empirical studies on the determinants of household electricity consumption and efficiency at macro level exist, lack of consensus in estimations and reporting of findings make applicability of results inappropriate in developing countries [29, 37-39]. As such, little is known about what drives household electricity consumption and efficiency in developing countries at micro level.

The main objective is to evaluate determinants of household energy efficiency and electricity consumption Uganda, which is helpful to find out the key factors that influence household energy use and efficiency in Uganda.

\section{Methodology}

\subsection{Theoretical measurement of energy usage and efficiency}

In measuring energy efficiency, economic foundations propose assessment of an individual conditional input demand frontier function like the demand function. An input demand frontier estimate using stochastic frontier approaches obtains its basis on existence of a purely non-negative error element (a measurement of inefficiency), the existence of over utilization or underutilization of energy could possibly cause econometric concerns, like wrong skewness of the non-negative element. Given the fact that most economic agents use energy saving technologies, it tends to favour the scenario that the observed electricity use ( $\left.\mathrm{E}_{\text {observed }}\right)$ is often higher than the optimal electricity use $\left(\mathrm{E}_{\text {frontier}}\right)$ as illustrated in Figure 2.1 


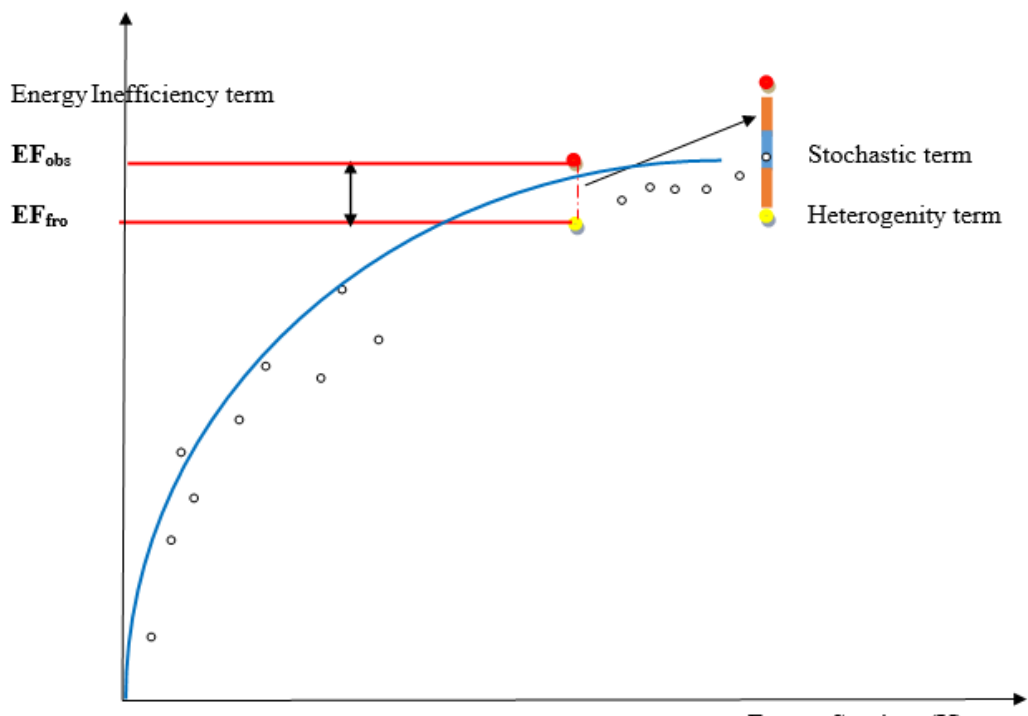

Energy Services $(\mathrm{Y})$

Source: Adopted from M Filippini [40] Figure 2.1: Energy Efficiency Determination

Energy efficiency thus measures the potential of a household to reduce the energy consumed, given a level of output (Y)

$$
\text { Energy Efficiency of household }\left(\mathrm{EE}_{i}\right)=\frac{1}{\text { Energy Inefficiency }}=\frac{E_{\text {Observed }}}{E_{\text {Frontier }}}, 0<\mathrm{EE}_{i} \leq 1
$$

An energy efficiency score of one indicates that a household is on the frontier (100\% efficient); while non-frontier households are characterized by a level of energy efficiency lower than $100 \%$, receive scores below one.

\subsection{Data source}

The study utilized cross-sectional secondary data from Uganda National Household Survey (UNHS) of 2016/17 that was conducted by the Uganda Bureau of Statistics (UBOS) from July 2016 to June 2017 since it's the latest data collected by the government on energy. The survey collected data on 3,310 households randomly selected from 4 regions of the country and comprised of a market survey and a socioeconomic module, both of which provide a better descriptive depiction of the economy, and deeper insight into factors affecting sustainable energy efficiency in Uganda. However, due to the case study under the research, a sample of 344 households (10 percent) was used based on Krejicie and Morgan table of sample size determination

\subsection{Estimation model for energy efficiency}

The paper employed a stochastic energy demand frontier function as proposed by A Alberini and M Filippini [11], M Filippini and LC Hunt [41] and A Otsuka [29] to estimate the level of electricity efficiency and the factors influencing electricity consumption and efficiency at household level. This study assumes that energy demand per household $\left(E C_{i}\right)$, is a function of several variables:

$E C_{i}=g\left(X_{i}, \beta\right)+\left(v_{i}+\mu_{i}\right)$

Where: $E C_{i}$ represents Annual energy consumption in $\mathrm{kWh}^{1} ; X_{i}$ represents vector variable of price of electricity per unit, household characteristics (household income, household size, geographical location) and institutional factors such as electricity mode of payment, $\beta$ represents the parameter of the estimate, $v_{i}$ represents the systematic component

${ }^{1}$ Annual electricity consumed in $\mathrm{kWh}$ will be generated from the annual expenditure on electricity consumption per household taking into consideration of the appropriate tariffs for domestic users during the year. 
which represents random disturbance term due to factors outside the scope of the households; $\mu_{i}$ represents the one sided disturbance term used to represent energy inefficiency and is independent of $v_{i}$.

In this study, the stochastic frontier approach (SFA) has been adopted because it is possible to determine whether a household is on the frontier (i.e., efficient) or not. The distance from the frontier indicates part of the electrical energy consumption exceeding baseline demand, called energy inefficiency. The stochastic frontier cost (minimizing) level of electrical energy consumption in equation (3.1) is based on energy price, given the level of income and other factors [42]. The empirical stochastic frontier energy demand function from equation (3.2) is specified as:

$\ln E C_{i}=\beta_{0}+\beta_{1} \ln X_{1 i}+\beta_{2} \ln X_{2 i}+\beta_{3} \ln X_{3 i}+\beta_{4} X_{4 i}+\beta_{5} X_{5 i}+\beta_{6} X_{6 i}+e_{i}$

Where $X_{1}=$ represents Annual household income in UGX, $X_{2}=$ represents price of electricity per unit in Uganda shillings (UGX), $X_{3}$ represents household size (persons), $X_{4}=$ represents number of rooms, $X_{5}=$ represents geographical location of the household and $X_{6}=$ represents electricity mode of payment; $\beta$ 's are parameters to be estimated, and $e$ is a disturbance term defined as $e_{i}=v_{i}+u_{i} \cdot v_{i}$ is normally distributed, $\mathrm{N}\left(0, \delta^{2}\right)$ and is assumed to be independent of $u_{i}$ and the explanatory variables while $u_{i}$ is a non-negative stochastic variable with distribution $\mathrm{N}\left(\mu, \delta_{\mu}{ }^{2}\right)$.

Given equation (3.2), the level of energy efficiency $\left(E E_{i}\right)$ is estimated using the conditional mean of the efficiency term E $\left(\mu_{i} \mid v_{i}+\mu_{i}\right)$ proposed by J Jondrow, CK Lovell, IS Materov and P Schmidt [43]. The level of energy efficiency $\left(E E_{i}\right)$ is measured by the ratio of observed energy consumption $\left(E C_{i}\right)$ to the estimated energy demand frontier $\left(E D_{i}\right)$.

$$
E E_{i}=E C_{i} / E D_{i}=e^{-\mu i}, 0<E E_{i} \leq 1
$$

Following the standard practice for stochastic frontier approach (SFA) by D Aigner, CK Lovell and P Schmidt [44], this study estimates the household level of underlying sustainable energy efficiency and identify the best practice system in terms of sustainable energy utilization. The empirical energy inefficiency part is thus specified as:

$\mu_{i}=\delta_{0}+\delta_{1} Z_{1 i}+\delta_{2} Z_{2 i}+\delta_{3} Z_{3 i}+\delta_{4} Z_{4 i}+\delta_{5} Z_{5 i}+\delta_{6} Z_{6 i}+\varepsilon_{i}$

Where $\delta$ 's are unknown parameters to be estimated, $Z_{1}=$ annual household income in UGX, $Z_{2}=$ annual household income squared in UGX, $Z_{3}$ =household size (number of persons), $Z_{4}=$ power availability, $Z_{5}=$ ownership status of the home residence, $Z_{6}=$ education level of the household.

A stochastic frontier approach (SFA) model of energy demand equation (3.2) together with the energy inefficiency model in equation (3.3) was estimated with the use of maximum likelihood estimate (MLE) technique in Frontier version 4.1 computer program [45].

When $\delta$ is negative, it implies an improvement in sustainable energy efficiency. Whether or not the energy inefficiency effects existed was verified using log-likelihood ratio (LR) test statistic computed from equation (3.5). $\chi^{2}=-2\left[\log \left(L\left(H_{0}\right)\right)-\log \left(L\left(H_{1}\right)\right)\right]$

Where $\chi^{2}$ has a chi-square distribution; $\mathrm{L}\left(\mathrm{H}_{0}\right)$ and $\mathrm{L}\left(\mathrm{H}_{1}\right)$ denote the values of the likelihood function under the null hypothesis (Ordinary Least Squares (OLS) model) and the alternative hypothesis (Stochastic Energy Frontier (SEF) model) respectively.

Since results in Table 1 further indicate the existence of inefficiency effects on domestic energy users, SEF (Stochastic Energy Frontier) was thus the most appropriate model for domestic energy users compared to OLS (ordinary least squares) leading to the rejection of the null hypothesis at 1 percent level. Hence traditional OLS could not adequately represent the sample data for domestic energy users.

Table 1: Hypotheses tests for model appropriateness and selection

\begin{tabular}{lcccc}
\hline Null Hypothesis & Log Likelihood & LR Statistic & Critical value & Decision \\
\hline 1. Ho: $\gamma=0$ & & & Mixed $\chi^{2}{ }_{5,0.01}$ & \\
No inefficiency among energy users & -289.959 & 17.258 & 14.325 & Reject Ho \\
$\begin{array}{l}\text { 2. Ho: } \delta_{0}=\delta_{1}=\cdots=\delta_{5}=0 \\
\text { Explanatory variables have no effects }\end{array}$ & -297.387 & 14.857 & $\chi^{2}{ }_{5,0.01}$ & \\
\hline
\end{tabular}

This publication is licensed under Creative Commons Attribution CC BY. 


\section{RESULTS AND DISCUSSION}

\subsection{The level of efficiency household in Uganda}

The overall electricity inefficiency effects were evaluated in terms of parameters estimates associated with $\delta$ and $\gamma$ (Table 2). The estimates of the variance parameters $\delta^{2}$ and $\gamma$ for domestic energy users (both heating and lighting) were significantly different from zero at 5 and 1 percent levels. This is an indication that the observed electrical energy consumed significantly differed from the estimated electrical energy demand frontier. Specifically, the value of gamma $(\gamma)$ of 0.746 for electrical energy consumers reveal that inefficiency effects are significant in determining the levels and variations of energy consumed. This implies that 74.6 percent of the variation in energy consumed respectively is due to the differences in energy efficiency rather than random variability. The results further depict that the systemic variations that were unexplained by the energy demand function are the dominant source of errors.

Table 2: Maximum Likelihood Estimates (MLE) of the Stochastic Energy Frontier Model

\begin{tabular}{llll}
\hline Variables & Parameter & Sample (n=344) \\
\cline { 3 - 4 } & & Coef. & Std. error \\
\hline Constant & $\beta_{0}$ & $1.224^{* * *}$ & 0.149 \\
lnHousehold income & $\beta_{1}$ & $0.432^{* * *}$ & 0.034 \\
InPrice of electricity & $\beta_{2}$ & $-0.014^{* * *}$ & 0.007 \\
lnHousehold size & $\beta_{3}$ & 0.014 & 0.067 \\
InHousehold number of rooms & $\beta_{4}$ & $0.166^{*}$ & 0.127 \\
lnHousehold residence & $\beta_{5}$ & $0.159^{* *}$ & 0.06 \\
Mode of payment through sharing & $\beta_{6}$ & $-0.341^{* * *}$ & 0.065 \\
Constant & $\delta_{0}$ & $-9.414^{*}$ & 5.443 \\
lnHousehold income & $\delta_{1}$ & $-0.078^{*}$ & 0.032 \\
lnHousehold size & $\delta_{2}$ & $-0.674^{*}$ & 0.424 \\
InPower availability & $\delta_{3}$ & $-0.641^{* *}$ & 0.316 \\
Ownership status of the house & $\delta_{4}$ & -0.311 & 0.223 \\
Education level of the household head & $\delta_{5}$ & $1.213^{*}$ & 0.742 \\
Sigma squared $\left(\delta_{u}{ }^{2}+\delta_{v}{ }^{2}\right)$ & $\delta^{2}$ & $1.061^{* *}$ & 0.452 \\
Gamma $\left(\delta_{u}{ }^{2} / \delta^{2}\right)$ & $\gamma$ & $0.775^{* * *}$ & 0.141 \\
LR test & $\chi^{2}$ & $17.164^{* * *}$ & \\
Log likelihood Ratio & & -278.149 & \\
Mean Energy Efficiency & $\mu$ & 74.6 & \\
\hline
\end{tabular}

Note: *, ** and *** show significance at 10, 5 and 1\% level, respectively

\subsection{Determinants of electricity consumption in Uganda}

As expected, in table 2 the price elasticity of electricity was found to be significant and negatively related to the quantity of electricity consumed at 1 percent level. Based on results in Table 4.3, a 1 percent increase in price of electricity would result into 0.029 percent reduction in the quantity of electricity consumed holding other factors constant. This is explained by the fact that household's behaviour towards increasing the share of energy saving technologies leads to a reduction in energy use per capita.

The effect of income variable on household electricity consumption was positive and statistically significant at 1 percent level. This finding suggests that a unit increase in the household level of income would increase energy use by 43.2 percent holding other factors constant. This result could be explained by the fact that richer people have more opportunities to satisfy their needs including investing in larger apartments, travelling longer distances among others. All these issues promote to higher energy use rates. 
ISSN 2250-3153

Other factors that had a positive and significant at 1 percent on electricity consumption were household residence with urban residents consuming more of energy compared to rural residents at 5 percent level. On contrary and expected, mode of payment for energy had a negative and significant influence on the amount of energy used at 1 percent level holding other factors constant. This result suggests that households' mode of energy payment via sharing were associated with reduced energy use.

\subsection{Determinants of energy efficiency in Uganda}

Energy efficiency was estimated for domestic users using equation (3.2) and (3.3). The factors that influence energy efficiency are presented in Table 1 above. In the interpretation of the results in the inefficiency model (Table 2 lower panel), positive signs of the coefficients indicate a decrease in energy efficiency since the inefficiency model has the electricity inefficiency as the dependent variable. The reverse is true for negative signs of the coefficients. The effect of household size was found to have a negative and statistically significant influence on energy efficiency at 10 percent level. The coefficient corresponding to household size indicates that when household size increases by one member, energy efficiency decreases by about 78.4 percent holding other factors constant. This result plays down the notion that households with large family size invest in energy-saving technologies.

Results in Table 2 further show that for domestic energy users, the influence of power availability on energy efficiency was negative and significant at 5 percent. This result suggests that domestic energy users whose power was available were inefficient. This could be attributed to the fact that households with large family size and have power throughout tend to use energy for many reasons including non-vital services. Other factors that had a significant influence on energy efficiency were household income and household level of education. The result on income of the household shows that at low income levels, residents are inefficient in the use of energy. However, when the income reaches a certain threshold that enables households to possess energy-efficient appliances sufficient to meet their needs household energy efficiency could improve.

\subsection{Energy Efficiency Distribution in Uganda}

An electricity efficiency score of 1 indicates highest efficiency and the lower the score, the lower the energy efficiency. Level of energy efficiency for the domestic electricity consumers ranged between 20.7 to 93.0 percent. The mean energy efficiency was 74.6 percent (Table 3 ). This implies that an average domestic energy user could save electrical energy by approximately 23.5 percent if it were to improve energy efficiency (EE).

Table 3: Distribution of energy efficiency estimates results

\begin{tabular}{lll}
\cline { 2 - 3 } Level of efficiency & Frequency & Percentage \\
\hline$<0.21$ & 01 & 0.3 \\
$0.21-0.3$ & 03 & 0.9 \\
$0.31-0.4$ & 02 & 0.6 \\
$0.41-0.5$ & 10 & 2.9 \\
$0.51-0.6$ & 25 & 7.3 \\
$0.61-0.7$ & 42 & 12.2 \\
$0.71-0.8$ & 92 & 26.7 \\
$0.81-0.9$ & 163 & 47.4 \\
$0.91-100$ & 06 & 1.7 \\
Number of Obs. & $\mathbf{3 4 4}$ & $\mathbf{1 0 0}$ \\
Mean & 0.746 & \\
Min & 0.207 & \\
Max & 0.930 & \\
\hline
\end{tabular}

This publication is licensed under Creative Commons Attribution CC BY. 
ISSN 2250-3153

These findings further show that if an average domestic energy users were to reach the EE level of his/her most efficient counterpart, then the average domestic energy user could experience an electrical energy saving of about 19.7 percent i.e. [(1- 0.746/0.930) x 100] This further suggests that there is potential to improve energy efficiency of an average domestic energy user given the level and type of energy saving technologies currently being used.

\subsection{Estimated potential electricity consumption and energy wasted at household level}

In order to measure energy wasted for domestic energy users, both the actual energy used and potential energy used were computed using equation (3.3). According to [46], the loss due to inefficiency is the difference between potential consumption and the actual consumption. Table 4 provides an account of the potential energy use as well as the energy wasted in electricity consumption at household level.

Table 4: Estimates of potential electricity consumption and energy wasted.

\begin{tabular}{llll}
\hline Variables & \multicolumn{3}{l}{ Domestic energy users (n=344) } \\
\cline { 2 - 4 } & Mean & Minimum & Maximum \\
\hline Observed electricity consumed $(\mathrm{kWh})$ & 402.97 & 24 & 4260 \\
Electricity efficiency estimates & 0.74 .6 & 0.207 & 0.930 \\
Computed energy frontier $(\mathrm{kWh})$ & 526.76 & 115.94 & 4580.65 \\
Computed energy wasted $(\mathrm{kWh})$ & 123.792 & 91.94 & 320.65 \\
\hline
\end{tabular}

The computed mean potential energy use was $526.76 \mathrm{kWh}$ for domestic energy users. The potential energy wasted due to inefficient use of electricity is based on the assumption that the average domestic energy user had an efficiency level of 100 percent without the requirement of additional usage of energy saving appliances. Therefore, on average domestic energy user wasted $123.79 \mathrm{kWh}$ due to energy inefficiency. This further translates into income loss of 88,437 Uganda shillings $(\mathrm{UGX})^{2}$ on annual basis.

\subsection{Policy implications}

Existing policies about increasing energy access specifically to rural areas and increasing share of renewable energy in the Uganda's energy mix. However there is no independent policy to legislate energy efficiency yet it plays an important role in increasing energy access rates.

Based on the findings and discussions on energy efficiency, there is still room to improve efficiency for domestic energy consumers with the existing energy conservation technologies and management practices. An Energy Efficiency and Conservation Bill should be undertaken not only to legislate towards better energy/electricity management in households but also in industries commercial and institutions and to enhance energy efficiency in other sectors.

Energy efficiency programmes on raising awareness can be used to encourage the adoption of new technologies and practices including application of energy-efficient gadgets and encouraging households to engage in energy conservation actions and best practices hence need to promote energy conservation actions and influence household decision-making. More so, saving of energy at household level by stimulation and support measures including introduction of new methods of energy use management, educating people through the electronic and print media and providing financial incentives in the form of subsidies in the price of energy efficient materials.

Additionally, there is need to ensure the sustainable development of energy use by introducing higher energy efficiency standards for energy appliances and diversifying household income sources could be vital. Furthermore, strategies for enhancing energy efficiency should focus on specific groups that tend to exhibit higher inefficiency in electricity usage. This study found that household size was associated with reduced energy efficiency. Hence, the decrease of energy efficiency driven by the change of household size should be a matter of concern.

${ }^{2}$ Each additional unit of electricity beyond 15 units was charged at 719 Uganda shillings (UGX)

This publication is licensed under Creative Commons Attribution CC BY.

http://dx.doi.org/10.29322/IJSRP.11.08.2021.p11629

www.ijsrp.org 


\section{CONCLUSION}

The efficiency level depends on the socio-economic characteristics and institutional factors whose influences were controlled for when deriving the efficiency scores resulting in a more accurate index. Based on the findings, we find that domestic energy consumption is inefficient in electricity usage and the potential loss in household energy consumption remains high on average in terms of annual income.

In addition, socio-economic factors and household characteristics as illustrated by electricity price and household income do matter, as they create significant variations in household energy use and efficiency. Household size and power availability had negative and significant influence on energy efficiency. In addition level of education enhanced electricity efficiency at household level.

Existing policies about increasing energy access specifically to rural areas and increasing share of renewable energy in the Uganda's energy mix. However there is no independent policy to legislate energy efficiency yet it plays an important role in increasing energy access rates.

\section{REFERENCES}

[1] Adeyemi K, Asere A: A review of the energy situation in Uganda. International Journal of Scientific and Research Publications 2014, 28(33,817,496):95.

[2] IEA: IEA (International Energy Agency). World Energy Outlook 2018. IEA, Paris. 2018.

[3] IEA: IEA (International Energy Agency). World Energy Outlook 2017. IEA, Paris. 2017.

[4] SGD: Tracking SDG7: The Energy Progress Report Highlights. The World Bank, Washington DC. 2019.

[5] Blimpo MP, Malcolm C-D: Electricity Access in Sub-Saharan Africa: Uptake, Reliability, and Complementary Factors for Economic Impact. Africa Development Forum series. Washington, DC: World Bank. . 2019.

[6] Phadke AA, Jacobson A, Park WY, Lee GR, Alstone P, Khare A: Powering a home with just 25 Watts of solar PV: Super-efficient appliances can enable expanded off-grid energy service using small solar power systems. 2017.

[7] Moolman S: Infographic: Eskom tariff increases vs inflation since 1988 (with projections to 2017). Poweroptimal 2015.

[8] du Can SdlR, Pudleiner D, Pielli K: Energy efficiency as a means to expand energy access: A Uganda roadmap. Energy Policy 2018, 120:354-364.

[9] SEforALL: Sustainable Energy for All (SEforALL). Uganda's SEforALL Investment Prospectus, EU Technical Assistance Facility for the "Sustainable Energy for All" Initiative (SEforALL). Eastern and Southern Africa SEforALL Investment Prospectus for Uganda. Prepared by Atkins Consulting. 2016a.

[10] Toman MT, Jemelkova BJTEJ: Energy and economic development: an assessment of the state of knowledge. 2003, 24(4).

[11] Alberini A, Filippini M: Response of residential electricity demand to price: The effect of measurement error. Energy economics 2011, 33(5):889-895.

[12] Filippini M, Hunt LCJEe: US residential energy demand and energy efficiency: A stochastic demand frontier approach. 2012, 34(5):1484-1491.

[13] Nadeem M, Mujaddid HG, Asghar N: Measuring energy efficiency and exploring the determinants of energy efficiency in selected economies of Asia. Review of Economics and Development Studies 2017, 3(2):135-146.

[14] Pelenur M: Household energy use: a study investigating viewpoints towards energy efficiency technologies and behaviour. Energy Efficiency 2018, 11(7):18251846.

[15] Fowlie M, Phadke A: Energy Efficiency in the Developing World. Policy 2017, 5:30-66.

[16] Hussaini IU: Households' energy efficiency practices in a bereft power supply economy of Nigeria. In: Energy-Efficient Approaches in Industrial Applications. IntechOpen; 2018.

[17] Ürge-Vorsatz D, Herrero STJEp: Building synergies between climate change mitigation and energy poverty alleviation. 2012, 49:83-90.

[18] Gillingham K, Newell RG, Palmer K: Energy efficiency economics and policy. Annual Review of Resource Economics 2009, 1(1):597-620.

[19] Ryan L, Campbell N: Spreading the net: the multiple benefits of energy efficiency improvements. 2012.

[20] Bazilian M, Nussbaumer P, Eibs-Singer C, Brew-Hammond A, Modi V, Sovacool B, Ramana V, Aqrawi P-KJTEJ: Improving access to modern energy services: insights from case studies. 2012, 25(1):93-114.

[21] Kasulis JJ, Huettner DA, Dikeman NJ: The feasibility of changing electricity consumption patterns. Journal of Consumer Research 1981, 8(3):279-290.

[22] Poortinga W, Steg L, Vlek C, Wiersma G: Household preferences for energy-saving measures: A conjoint analysis. Journal of Economic Psychology 2003, 24(1):4964.

[23] Walsh MJ: Energy tax credits and housing improvement. Energy Economics 1989, 11(4):275-284.

[24] Gamtessa SF: An explanation of residential energy-efficiency retrofit behavior in Canada. Energy and Buildings 2013, 57:155-164.

[25] Anderson W, White V, Finney A: You just have to get by': coping with low incomes and cold homes. Bristol: Centre for Sustainable Energy, Eaga Charitable Trust, Kendal. 2010.

[26] Brunner K-M, Spitzer M, Christanell A: Experiencing fuel poverty. Coping strategies of low-income households in Vienna/Austria. Energy Policy 2012, 49:53-59.

[27] Campbell N, Ryan L, Rozite V, Lees E, Heffner G: Capturing the multiple benefits of energy efficiency. International Energy A gency, Paris, France. 2014.

[28] Young D: When do energy-efficient appliances generate energy savings? Some evidence from Canada. Energy Policy 2008, 36(1):34-46.

[29] Otsuka A: Regional determinants of energy efficiency: Residential energy demand in Japan. Energies 2018, 11(6):1557.

[30] Dergiades T, Tsoulfidis L: Estimating residential demand for electricity in the United States, 1965-2006. Energy Economics 2008, 30(5):2722-2730.

[31] Sanquist TF, Orr H, Shui B, Bittner AC: Lifestyle factors in US residential electricity consumption. Energy Policy 2012, 42:354-364.

[32] Winkler H, Simões AF, La Rovere EL, Alam M, Rahman A, Mwakasonda S: Access and affordability of electricity in developing countries. World Development 2011, 39(6):1037-1050.

[33] Adewale AA, Adekitan AI, Idoko OJ, Agbetuyi FA, Samuel IAJCE: Energy audit and optimal power supply for a commercial building in Nigeria. 2018, $5(1): 1546658$. 


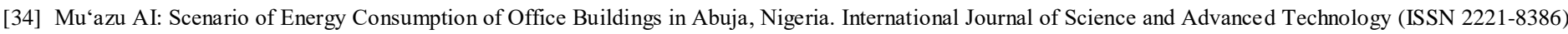
Volume 2012, 2.

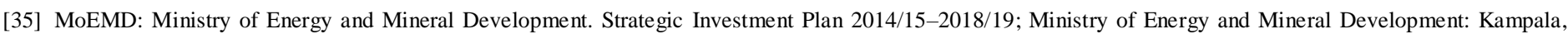
Uganda, 2014. 2014.

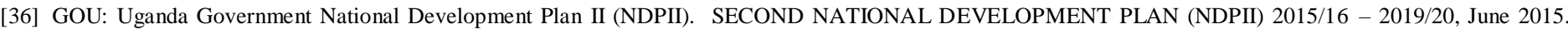
Kampala, Uganda. 2015.

[37] Huang W-H: The determinants of household electricity consumption in Taiwan: Evidence from quantile regression. Energy 2015, 87:120-133.

[38] Kim M-J: Characteristics and determinants by electricity consumption level of households in Korea. Energy Reports 2018, 4:70-76.

[39] Keho Y: What drives energy consumption in developing countries? The experience of selected African countries. Energy Policy 91 : 233-246. 2016.

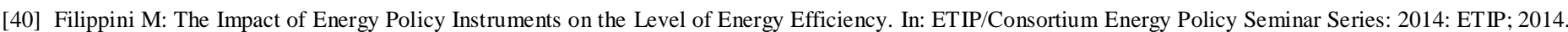

[41] Filippini M, Hunt LC: Measurement of energy efficiency based on economic foundations. Energy Economics 2015, 52:S5-S16.

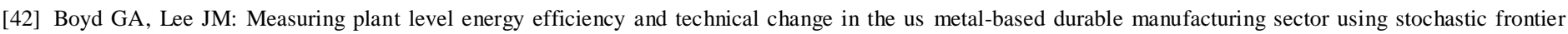
analysis. Energy Economics 2019, 81:159-174.

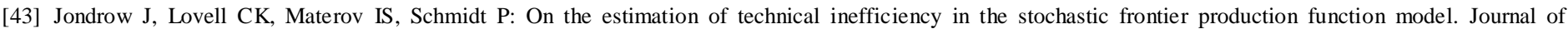
econometrics 1982, 19(2-3):233-238.

[44] Aigner D, Lovell CK, Schmidt P: Formulation and estimation of stochastic frontier production function models. Journal of econometrics 1977, 6(1):21-37.

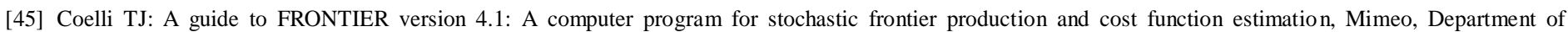
Econometrics, University of New England, Amidale. 1996.

[46] Mor S, Sharma SJAE: Technical efficiency and supply chain practices in dairying: The case of India. 2012, 58(2):85-91.

\section{AUTHORS}

First Author - Muwanga ALLAN, UN Environment Tongji-Institute of Environmental for Sustainable Development, College of Environmental Science and Engineering, Tongji University, Shanghai 200092, China.

Second Author - Ru Guo, College of Environmental Science and Engineering, Tongji University, 1239 Siping Road, Shanghai 200092, P.R. China 